\title{
Collection Facilitator
}

National Cancer Institute

\section{Source}

National Cancer Institute. Collection Facilitator. NCI Thesaurus. Code C53426.

A substance used to increase the quality or quantity of a sample harvest. 